\title{
Ocean Wave Prediction Using Numerical and Neural Network Models
}

\author{
S. Mandal* and N. Prabaharan \\ National Institute of Oceanography, Dona Paula, Goa 403004, India
}

\begin{abstract}
This paper presents an overview of the development of the numerical wave prediction models and recently used neural networks for ocean wave hindcasting and forecasting. The numerical wave models express the physical concepts of the phenomena. The performance of the numerical wave model depends on how best the phenomena are expressed into the numerical schemes, so that more accurate wave parameters could be estimated. There are still scopes for improving the numerical wave models. When exact input-output parameters are known for the same phenomenon, it can be well defined by the neural network. Hindcasting of ocean wave parameters using neural networks shows its potential usefulness. It is observed that the short-term wave predictions using neural networks are very close to the actual ones. It is also observed that the neural network simplifies not only the complex phenomena, but also predicts fairly accurate wave parameters.
\end{abstract}

Keywords: Ocean waves, operational wave models, neural networks, online wave prediction.

\section{INTRODUCTION}

The importance of the ocean wave prediction was first felt in early 1940's for the planning of Naval fleet operations during the second world war. The wave prediction method was first proposed based on the simple empirical formulations [1]. Subsequently, many first and second generation numerical models were developed during last few decades and presently, a few including third generation operational wave models exist for wave forecasting. With the rapid developments in the computer technology, the success of complicated numerical wave prediction models is possible. Unless the phenomena are exactly numerically expressed, the uncertainty of accurate prediction remains. The expressed relation between wind and other inputs and wave parameters may need further improvement for these numerical wave models.

The numerical wave models developed were based on energy balance equation with various components of the source function as inputs. One of the inputs, which could not be fully analyzed till late 1970 's, was the non-linear wavewave interaction [2]. The third generation operational wave models use the components of the source function without any prior restrictions on the spectral shape [3]. Even though the third generation wave models fairly predict waves, one can still improve the models by better representation of extremely complex physical processes of wind generated waves $[4,5]$.

The neural network has the ability to recognize the hidden pattern in the data and accordingly estimate the target values. Provision of model-free solutions, data error tolerance, built in dynamism and lack of any exogenous input requirement makes the neural network attractive. A neural network is an information processing system modelled on the structure of the dynamic process. Its merit lies in the abil-

*Address correspondence to this author at Ocean Engineering Division, National Institute of Oceanography, Goa 403004, India: Tel: 918322450265; Fax: 91-8322450604; E-mail: smandal@nio.org

1874-835X/10 ity to deal with information whose interrelation is ambiguous or whose functional relation is not clear. Some applications of neural networks in wave hindcasting and forecasting are described based on recent work carried out by various authors [6-10]. Krasnopolsky, Chalikov and Tolman [11] have used neural network to develop a computationally cost effective and accurate approximation for non-linear wavewave interaction source term of the energy balance equation.

Recent trend of neural networks in ocean wave prediction shows that it has potential usefulness. In numerical models, we have many assumptions, boundary conditions, simplification of nonlinear wave-wave interaction, etc. Whereas there are no priori restrictions in the neural network models. The neural network does not recognise the physical phenomena. It establishes the relationships between inputs and outputs based on learning processes. The wave predictions using numerical models and neural networks are briefly described in this paper. Some recent results on predictions of ocean wave parameters using neural networks are also presented.

\section{NUMERICAL WAVE MODELS}

In general, the evolution of a surface wave field in space and time is defined by the energy balance equation

$$
d S(\mathrm{f}, \theta, \mathrm{x}, \mathrm{t}) / d t=S=I n+N l+D i s
$$

where, two-dimensional wave spectrum $S(\mathrm{f}, \theta, \mathrm{x}, t)$ is dependent on frequency $\mathbf{f}$, propagation direction $\boldsymbol{\theta}$, and defined over the geographic coordinates $\mathbf{x}$ and time $\boldsymbol{t}$. The left-hand side of Equattion-1 is the full derivative of the spectrum with time and the right-hand side is the source function $S$ depending on both the wave spectrum and on the external wavemaking factors such as local wind and local current.

It is generally used to distinguish three terms in the source function $S$, namely $I n=$ the mechanism of the energy exchange between the atmosphere and ocean waves, $\mathrm{Nl}=$ the energy conservative mechanism of nonlinear wave-wave interactions, and Dis = the dissipation, i.e., wave energy loss mechanism related to wave-breaking processes and interaction of waves with turbulence of the upper water layer. 
Precisely the differences in the presentation of the above components of the source function determine general differences between wave models.

Numerical wave prediction models which were developed are divided into four categories, i.e., First, Second, Third and Improved third generation wave models.

\section{FIRST GENERATION MODELS}

The first generations wave models are developed based on simple wind fields (In) and without dominating nonlinear interactions $(N l)$ and energy loss $(D i s)$, as at that time very little was known about any three source function components. However, theories of wave generation proposed by Phillips [12] and Miles [13] and later with Phillips' concept of universal equilibrium range of the spectrum [14], and Hasselmann's analysis of the non-linear energy transfer owing to wave-wave interactions [15-17], then provided a broader theoretical framework for the wave models.

The first empirical wave model was developed and introduced a parametric description of the sea state and used empirical wind sea and swell [1]. Thereafter, Pierson, Nuemann and James developed a model called PNJ-model for estimating wave conditions created by the distance storm [18]. This is based on the generated wave energy spreads over the ocean as distance to the generating storm increases. A modified version of PNJ- model was used by Darbyshire [19]. In this model it was assumed that the sea state was fully developed after 12 hours and $200 \mathrm{~nm}$ of constant wind. A model for ideal condition was proposed by Wilson [20] and it was further extensively studied [21, 22]. This is published in form of a handbook by WMO [23]. Seymour [24] proposed a directional de-coupling model where a stationary homogeneous wind field is considered over a deep-water basin with an arbitrary geometry of the coastline. The wave model applicable to tropical hurricanes was developed [25], where nondimensional radial distance from the point of the forecast to the eye of the hurricane is one among the characteristics of wind parameters.

\section{SECOND GENERATION MODELS}

The second generation wave models are developed using varying wind fields and simplified nonlinear interactions. Here, the sea surface is defined as the sum of a large number of individual wave components, each wave propagating with constant frequency according to the linear wave theory. The path of wave components (from origin to the forecast point) is calculated by the conventional methods. After leaving the origin, the wave component interacts with the other wave components. Thus at regular interval of time the energy gained or released in the process can be evaluated till it reaches the forecast point. This procedure can be repeated for a large number of wave components of different frequencies and directions at a given time so that the total energy is obtained at the point of forecast. A large group of wave experts on wave models (SWAMP) have made an attempt to interpret all the available models for inter-comparison [26], where wave models are clearly distinguished as decoupled propagation (DP), coupled hybrid $(\mathrm{CH})$ and coupled discrete (CD) models. In general, first generation models are of DP type. Most of the second generation models are of $\mathrm{CD}$ or $\mathrm{CH}$ type. The SWAMP has shown a clear variation of source function components for first-generation and secondgeneration models. The updated source function components (second-generation) are established based on extensive analysis and field measurements of wave growth under uniform fetch-limited wind condition [27-29].

The numerical wave prediction model DOLPHIN is a deep water hybrid point model, a combination of the parametric wind-sea and spectrally treated swells [30]. The development of this model is based on the directionally decoupled energy distribution of wind generated waves. Inputs to the model are wind field and coastal boundary. Outputs are significant wave height $\mathrm{Hs}$, variance density spectra giving information on the two-dimensional distribution of wave energy. By using this model wave parameters are computed over period where observed data is also available [31]. Three hourly values of Significant wave height (Hs), zero-crossing period, Maximum energy and peak period computed by hindcast model and those based on measured data seems to be quite good between computed and measured Hs values. The wave spectra predicted by the model and the measured wave spectra seem to be reasonably in good agreement.

\section{THIRD GENERATION MODELS}

The third generation wave models are developed to further improvement of modelling process. The Discrete Interaction approximation (DIA) is introduced in wave modeling [2]. The operational wave models, such as WAM [32, 33], SWAN [34] and WAVEWATCH III [35] are the third generation wave models. Even though wave modelling is being carried out for many decades, further improvement is being performed by incorporating the updated subroutines in these wave models. One of these is the improved parameterization of nonlinear quadruplet wave-wave interactions for application in operational wave prediction models [4]. The DIA has some shortcomings, which hamper the further development of the third generation wave model. These models use the energy balance equation for describing the time and space evolution of wave spectra. Further improvements are being carried out to obtain a fast and accurate method for computing the nonlinear quadruplet wave-wave interactions in deep and shallow water, such that this method can be applied in operational wave prediction models. For reaching a closer values of nonlinear energy transfer, neural network parameterization has been developed [11]. In this neural network integration approximation (NINA) is considered to estimate nonlinear interactions, $\operatorname{Snl}(\mathrm{f}, \theta)$ as a function of frequency $\mathrm{f}$ and direction $\theta$. from the corresponding spectrum, $F(f, \theta)$ in deep water. To train and test this NINA, they used a set of 20,000 simulated realistic spectra for $\mathrm{F}(\mathrm{f}, \theta)$ and the corresponding exact estimates of $\operatorname{Snl}(f, \theta)$. Simulation was based on spectral function of P-M spectra for different peak frequencies oriented randomly in $(0,2 \pi)$ interval. The NINA gives reasonable results and implemented for WAVE WATCH III model.

Recently, wind-wave variability in the shallow tidal basin of German Wadden Sea is modeled with the combination of SWAN [34] and principal component analysis (PCA) based neural network models [36]. Here the wave propagation and transformation in the study area are modeled using SWAN model. Then PCA based feed forward neural network model- 
ing of the mean wave parameters in the whole study area is carried out.

\section{IMPROVED THIRD GENERATION MODELS}

By modifying the wind wave model - WAM, a series of numerical experiments $[5,37]$ are carried out for verification of a proposed source function. Verification is done on the basis of comparison of the results of wave simulation for a given wind field with the buoy observation data obtained in three oceanic regions (Barents Sea, eastern and western parts of North Atlantic Ocean). For a series of wind wave parameters, estimations of simulation accuracy are obtained, and their comparison for original and modified WAM model is undertaken. The modified third generation model shows an enhancement of speed of calculation by $20-25 \%$ and an decrease of root mean- square simulation errors by 1.5-2 times for the significant wave height and the mean wave period. All modern numerical models for wind waves are based on the solution of the evolution equation for two-dimensional wave spectrum $S(\mathbf{k}, \mathbf{x}, t))$ given in the space of wave vectors $\mathbf{k}$ and defined over the geographic coordinates $\mathbf{x}$ and time $t$; and the updated source function components of Equation-1 are described in [5]. In particular, different generations of the models are classified by means of accounting for the degree of justification of parameterization for the $\mathrm{Nl}$-term. Differences in representation of the left-hand side of Equation-1 and in realization of its numerical solution are mainly related to the mathematics of wave models and also determine their particular features.

The measured wave data from British (eastern part of North Atlantic) and American (western part of North Atlantic) buoys for January 2006 are used to compare with WAM and improved NEW models as shown in Table 1 [5]. The predicted wave parameters (Hs and Tm) show an improvement with the new model as compared to WAM model.

Even though the new model performs better than WAM model, still there are scopes to improve further by finer fitting of all terms of the source function and use of accurate wind field.

Table 1. Root-Mean-Square Errors Between Observed and Predicted Wave Parameters

\begin{tabular}{|c|c|c|c|c|c|c|}
\hline \multirow{2}{*}{ MODEL } & \multicolumn{5}{|c|}{ Western Part of North Atlantic Buoys } \\
\cline { 2 - 7 } & \multicolumn{2}{|c|}{$\mathbf{4 4 1 3 8}$} & \multicolumn{2}{|c|}{$\mathbf{4 4 1 4 1}$} & \multicolumn{2}{c|}{$\mathbf{4 4 1 3 7}$} \\
\hline \hline \multirow{2}{*}{ Hs, $\mathrm{m}$} & $\mathrm{Tm}, \mathrm{s}$ & $\mathrm{Hs}, \mathrm{m}$ & $\mathrm{Tm}, \mathrm{s}$ & $\begin{array}{c}\text { Hs, } \\
\mathrm{m}\end{array}$ & $\mathrm{Tm}, \mathrm{s}$ \\
\hline NEW & 1.00 & 0.6 & 0.73 & 0.42 & 0.45 & 0.69 \\
\hline WAM & 1.19 & 0.8 & 0.88 & 0.51 & 0.51 & 0.81 \\
\hline & \multicolumn{5}{|c|}{ Eastern Part of North Atlantic Buoys } \\
\hline NEW & \multicolumn{2}{|c|}{64046} & & 64045 & 62105 \\
\hline WAM & 1.75 & 2.8 & 1.26 & 3.8 & 1.14 & 3.5 \\
\hline
\end{tabular}

\section{NEURAL NETWORK IN WAVE HINDCASTING}

The work carried out by Rao and Mandal [38] describes hindcasting of wave heights and periods from cyclone generated wind fields using neural networks. The back-propagation neural network with Rprop updated algorithm are used to estimate the wave heights and periods ( 2 outputs) based on storm parameters (3 inputs), i.e., difference in central and peripheral pressure, radius of maximum wind and speed of forward motion of cyclone. The network structure of $\mathrm{I}_{3} \mathrm{H}_{2} \mathrm{O}_{2}$ is shown in Fig. (1).

The storm field variables namely central pressure, radius of maximum wind, storm speed, direction of movement of storm, latitude and longitude are extracted for each cyclone from the isobaric charts available with the archives of the Indian Meteorological Department (IMD) at 3/6 hours time intervals.

The method based on standard Hydromet pressure profile is used for the hindcast of storm wind fields [39]. Young's model is used in the estimation of wave characteristics for the cyclones considered [40]. The input parameters to the model are radius of maximum wind, the maximum wind speed and the speed of forward motion. Using the JONSWAP fetch-limited growth relationship, the model estimates the maximum significant wave height and the spectral peak period of the maximum waves in the storm.

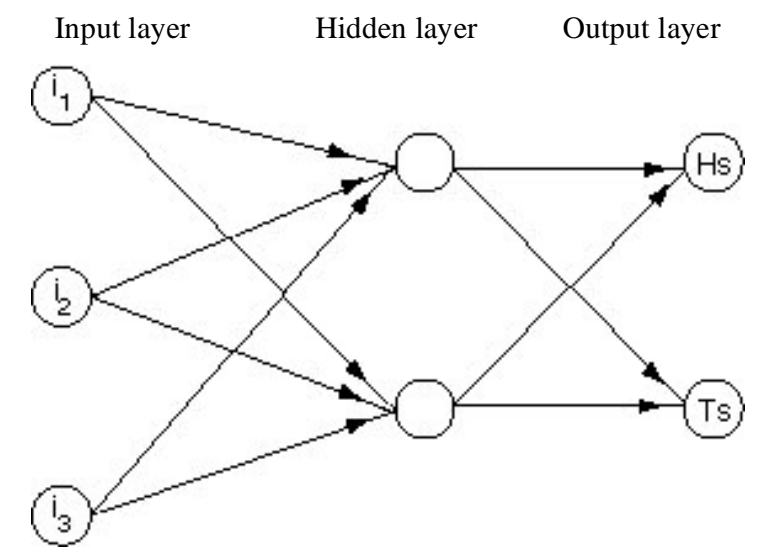

$i_{1}$ Difference in pressure

$\mathrm{i}_{2}$ Radius of maximum wind

$\mathrm{i}_{3}$ Speed of forward motion

Hs Wave height

Ts Wave period

Fig. (1). Neural network structure.

Correlation between wave height estimated using Young model and neural network yields the correlation coefficient of 0.99 and similarly correlation coefficient for wave period gives a value of 0.97 . This shows that neural network with Rprop updated algorithm can be used as an effective tool in estimating cyclone generated wave parameters.

\section{NEURAL NETWORKS IN WAVE FORECASTING}

Deo and Naidu [6] describe the application of neural network analysis in forecasting of significant wave height (Hs) with 3 hour lead period. They have carried out various combinations of training patterns to obtain the desired output 


$$
\text { Input layer Hidden layer } \quad \text { Output layer }
$$

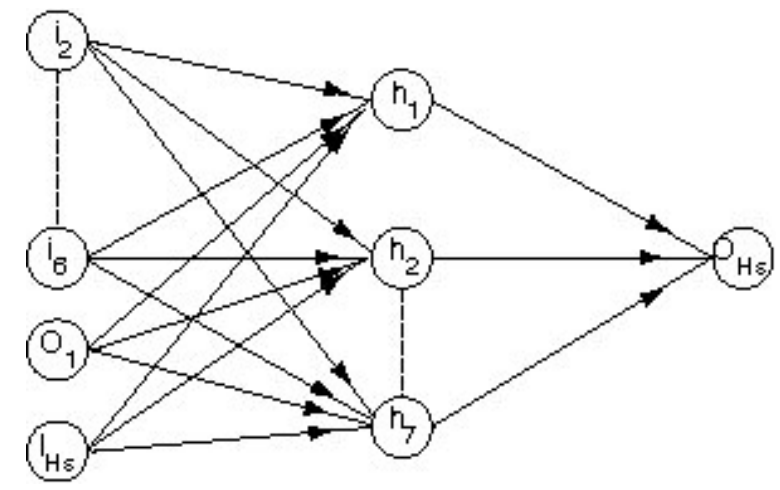

$\mathrm{i}_{2}-\mathrm{i}_{6}$ values taken from earlier output backwards

$\mathrm{O}_{1} \quad$ values taken from immediate output

$\mathrm{I}_{\mathrm{Hs}} \quad$ Input Hs value

$\mathrm{O}_{\mathrm{Hs}} \quad$ Output Hs value

Fig. (2). NARX recurrent network.

in addition to the work of average $12 \mathrm{hr}$ and a day wave forecasting. In this work the back-propagation, cascade correlation and conjugate gradient methods are used with the input layer of one node. The correlation coefficients obtained for the lead of 3 hour, half day and a day are $0.81,0.78$ and 0.71 respectively. Using updated algorithms in back-propagation neural network, the wave forecasting yielded better results as shown in [10]. Improved correlation coefficients for the lead of 3 hour, half-day and a day were obtained as $0.93,0.80$ and 0.73 respectively. The use of neural network for wave forecasting for three different sets of data is demonstrated in [7]. It shows that a proper trained network could yield good results in open wider areas, in deep water and also when the sampling and prediction interval are large (say, week).

Significant wave heights are forecasted using recurrent neural networks [9]. Here Memorization and NARX (Nonlinear AutoRegressive models with exogenous inputs) recurrent algorithms are used in back-propagation neural network. In the NARX network there is a provision to take values from the input layers and then shift them along the input layer as more patterns are added. For example, if we want to take a hidden unit value or an output unit value and keep them for more than a single time step, in effect a history of what the recent values have been. For the normal network combination of 1-7-1 the NARX network of the following combination is used as 7-7-1 with the input coming from the preceding output values.

Fig. (2) shows the neural network structure of $\mathrm{I}_{7} \mathrm{H}_{7} \mathrm{O}_{1}$, i.e., combination of 7-7-1 where the input value is one and the other values are taken from memorization of earlier sequences.

The wave data collected off Marmugao port, west coast of India at 23m water depth during February 1996 and January 1997 are used for the present studies. Three hourly significant wave heights (Hs) over the period are considered for the neural network. The time series of the forecasted three hourly Hs (NARX network) with the measured three hourly Hs show that the forecasted waves are closely matching with the measured values. The three hourly wave forecasting by memorization network has estimated the $\mathrm{CC}$ of 0.95 for NARX network (Fig. 3). Six hourly averaged significant wave height is forecasted and CC is 0.90. Twelve hourly (half-day) averaged wave forecasting data yields CC of 0.87 . In this also the up and down of wave profile is picked up by the forecast profile. The day averaged forecasting Hs yields the correlation coefficient value of 0.73 .

It can be seen that for even averaged wave data the improved results are obtained. Further improvement of wave forecasting using feed forward neural network and Levernberg-Marquardt algorithm is observed by Jain and Deo [41]. The comparative values of correlation coefficients are shown in Table 2. The correlation coefficient for 3 hourly $\mathrm{Hs}$ has improved from 0.81 to $0.99[6,41]$.

Table 2. Comparison of Correlation Coefficients for Hs

\begin{tabular}{|c|c|c|c|c|}
\hline $\begin{array}{c}\text { Fore- } \\
\text { casting } \\
\text { Lead } \\
\text { Time }\end{array}$ & $\begin{array}{c}\text { Deo and } \\
\text { Naidu, } \\
\text { [6] }\end{array}$ & $\begin{array}{c}\text { Subba Rao, } \\
\text { Mandal and } \\
\text { Prabaharan } \\
{[\mathbf{1 0}]}\end{array}$ & $\begin{array}{c}\text { Mandal and } \\
\text { Prabaharan, } \\
\text { [9] }\end{array}$ & $\begin{array}{c}\text { Jain and } \\
\text { Deo, } \\
{[\mathbf{4 1}]}\end{array}$ \\
\hline \hline $3 \mathrm{hr}$ & 0.81 & 0.93 & 0.95 & 0.99 \\
\hline $6 \mathrm{hr}$ & -- & 0.88 & 0.90 & 0.98 \\
\hline $12 \mathrm{hr}$ & 0.78 & 0.80 & 0.87 & 0.97 \\
\hline $24 \mathrm{hr}$ & 0.71 & 0.73 & 0.73 & 0.95 \\
\hline
\end{tabular}

The wave forecasting carried out is the next immediate value based on the present values. The forecasted Hs values for six and twelve hours also give good results. Using this method the Hs can be known in advance up to a period of twelve hours which will be useful for planning operation in the sea, such as pilot deep sea mining in the sea or undertaking any sub sea installation which requires advance information in sea conditions.

Tsai, Lin and Shen [8] have used back-propagation neural network to forecast the ocean waves based on learning characteristics of observed waves. The network structure of $\mathrm{I}_{8} \mathrm{H}_{4} \mathrm{O}_{1}$ is used. The network evaluates the interconnection weights among multi-stations based on previous short-term data.

Thereafter, a time series of waves at a station are forecasted based on using the neighbouring stations data [42]. A Graphical User Interface (GUI) integrating neural network model has demonstrated to obtain the wave forecasts at any of the locations considered through a web based operation [41].

The neural network does not explain physical processes taking place for generating ocean waves. To generate ocean waves, if exact input-output parameters are continuously known, the neural network can be trained using known input-output values, similar to validation of the numerical wave model.

There after predicting ocean wave parameters could be easier in the case of neural network as compared to the nu- 

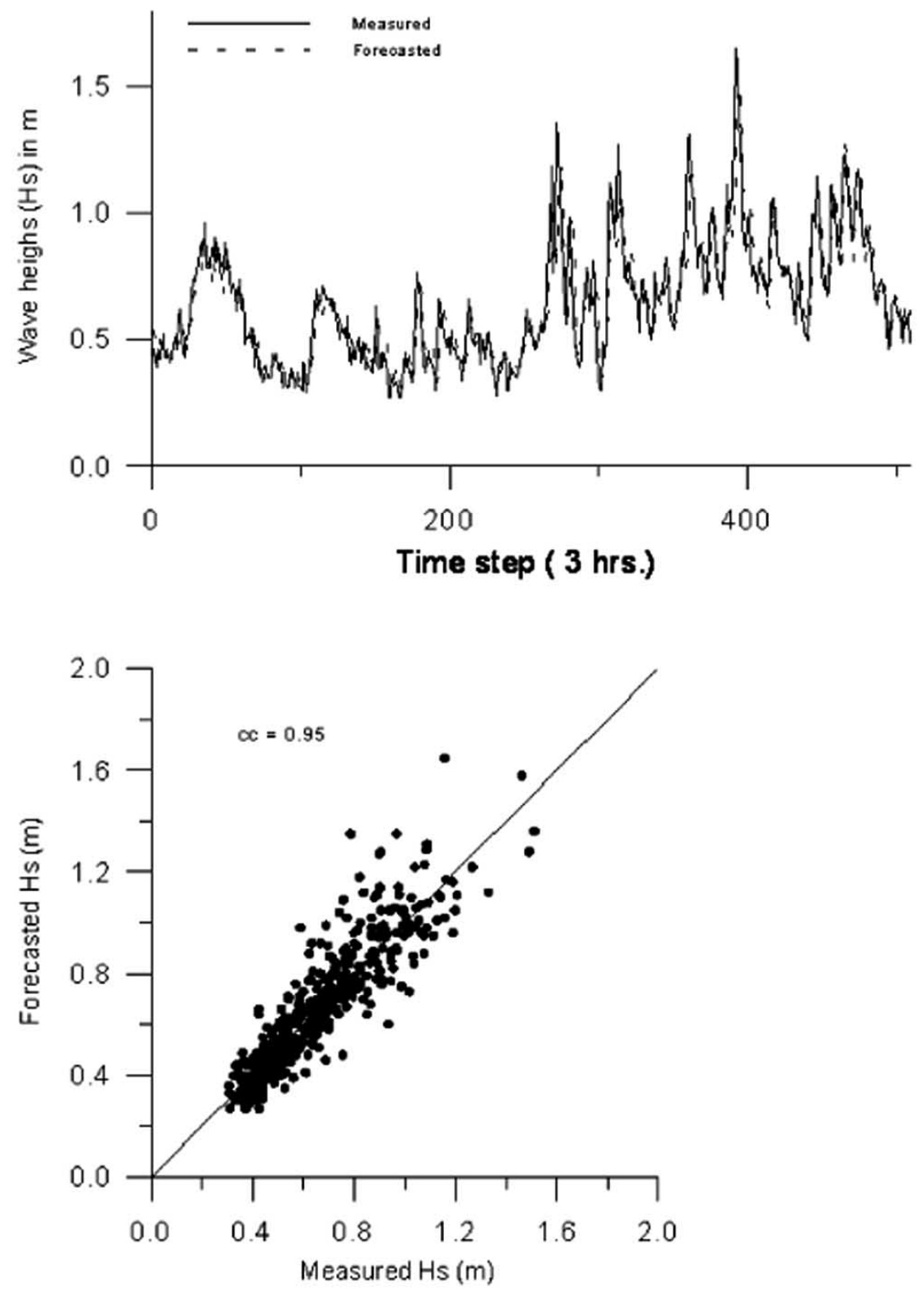

Fig. (3). Forecasted (3 hrs) waves off Marmugao by NARX network.

merical wave model. This is owing to simplicity of neural network connecting where weights are to be fixed based on known input-output values.

\section{CONCLUSIONS}

The numerical wave models play an important role for providing proper wave information for entire regional area or over many grid points.

The use of neural network for wave prediction has direct application by incorporating in the numerical wave modeling for solving complex nonlinear functions in an efficient way.

Jain and Deo [41] have demonstrated the use of GUI integrated neural network for on-line forecasting of ocean waves at any of the locations considered through a web based operation.
A detailed study can be made for a particular location using different numerical models and also with the neural network. For a particular location the neural network can be trained based on known inputs-outputs, which is similar to the validation of the numerical wave model. Thereafter, wave prediction can be carried out for unknown inputs. For short term prediction of ocean waves the neural network can be trained for which the data are available during the immediate earlier period and thereafter it can be used for wave forecasting for that location.

\section{ACKNOWLEDGEMENTS}

The authors are grateful to Director, National Institute of Oceanography (NIO), Goa, India for his encouragement. The authors are thankful to staff of Ocean Engineering Division, NIO, Goa for providing the measured wave data used for neural network modeling. NIO contribution number is 4643 . 


\section{REFERENCES}

[1] H.U. Sverdrup, and W.H. Munk, Wind, sea and swell: Theory of relation for forecasting: H.O. Publication 601 US Naval oceanographic office Washington DC, USA, 1947.

[2] S. Hasselmann, and K. Hasselmann, "Computations and parameterizations of the nonlinear energy transfer in a gravity wave spectrum, Part I and II," J. Phys. Oceanogr., vol. 15, pp. 1369-1391, 1985.

[3] H.L. Tolman, and D.V. Chalikov, "Source terms in a thirdgeneration wind wave model," J. Phys. Oceanogr., vol. 26, pp. 2497-2518, 1996.

[4] G.Ph. Van Vledder, "Extension of the Discrete Interaction Approximation for computing nonlinear quadruplet wave-wave interactions in operational wave models", In: $4^{\text {th }}$ ASCE International Symp. Ocean Waves, Meas. Anal., San Francisco, California, USA, 2001, pp. 540-549.

[5] V.G. Polnikov, V.I. Dymov, T.A. Pasechnik, I.V Lavrenov, and Y.N. Abuzyarov, "Real merits of the wind wave model with an optimized source function", Doklady Earth Sciences, Pleiades Publishing Ltd, vol. 417A (9), pp. 1375-1379, 2007.

[6] M.C. Deo, and C.S. Naidu, "Real time wave forecasting using neural networks," Ocean Eng., vol. 26, pp. 191-203, 1999.

[7] M.C. Deo, A. Jha, A.S. Chaphekar, and K. Ravikant, "Neural networks for wave forecasting," Ocean Eng., vol. 28, pp. 889-898, 2001.

[8] C-P. Tsai, C. Lin, and J-N. Shen, "Neural network for wave forecasting among multi-stations," Ocean Eng., vol. 29, pp. 1683$1695,2002$.

[9] S. Mandal, and N. Prabaharan, "Wave forecasting using recurrent neural networks," Ocean Eng., vol. 33, pp. 1401-1410, 2006.

[10] Subba Rao, S. Mandal, and N. Prabaharan, "Wave forecasting in near real time basis using neural networks," In: Int. Conf. Ocean Eng. (ICOE' 01), IIT Madras 2001, pp. 103-108.

[11] H.L. Tolman, V.M. Krasnopolsky, and D.V Chalikov, "Neural network approximations for nonlinear interactions in wind wave spectra: direct mapping for wind seas in deep water," Ocean Model., vol. 8, no. 3, pp. 253-278, 2005.

[12] O.M. Phillips, "On the generation of waves by turbulent wind," $J$. Fluid Mech., vol. 2, pp. 417-445, 1957.

[13] J.W. Miles, "On the generation of surface waves by shear flows," $J$. Fluid Mech., vol. 3, pp. 185-205, 1957.

[14] O.M. Phillips, "The equilibrium range in the spectrum of windgenerated ocean waves", J. Fluid Mech., vol. 4, pp. 426-436, 1958.

[15] K. Hasselmann, "On the nonlinear energy transfer in a gravity wave spectrum -1: general theory," J. Fluid Mech., vol. 12, pp. 481-500, 1962.

[16] K. Hasselmann, "On the nonlinear energy transfer in a gravity wave spectrum -2: conservation theorems, wave particle correspondence, irreversibility," J. Fluid Mech., vol. 15, pp. 273-281, 1963.

[17] K. Hasselmann, "On the nonlinear energy transfer in a gravity wave spectrum -3: Computation of the energy flux and swell-sea interaction for a Neumann spectrum," J. Fluid Mech., vol. 15, pp. 385-398, 1963b.

[18] W.J. Pierson, G. Neumann, and R.W. James, Practical Method for Observing and Forecasting Ocean Wave, U.S. Navy Hydro, Office Publication, 1955, No. 603.

[19] J. Darbyshire, "Prediction of wave characteristics over the North Atlantic," J. Inst. Navigation, vol. 14, pp. 339-347, 1961.

[20] B.W. Wilson, "Graphical Approach to the Forecasting of Waves in Moving Fetches", U.S. Beach Erosion Board, Corps of Engineers, Dept. of the Army Techn. Memo., No. 73, pp. 1-31, 1955.

[21] C.L. Bretschneider, Significant wave hindcast for station I. North Atlantic Storm, Dec. 1959, Tech Report no. SN-77-1, 1963.
[22] T.P. Barnett, and J.C. Wilkerson, "On the generation of ocean wind waves as inferred from airborne measurements of fetch-limited spectra”. J. Mar. Res., vol. 25, pp. 292-328, 1967.

[23] WMO, Handbook on Wave Analysis and Forecasting, World Met. Orgn. Geneva. WMO. no. 446, 1976.

[24] R.J. Seymour, "Estimating wave generation on restricted fetches", In: Proc. ASCE J. of Waterway Port, Coastal and Ocean Div., vol. 103(2), pp. 251-264, 1977.

[25] D. Ross, and V. Cardone, "A comparison of parametric and spectral hurricane wave prediction products": In: Conf. Turbulent Fluxes than the sea surface, wave dynamics prediction. Marseille, France: Plenum Press, Sept. 12-16, 1978, pp. 647-665.

[26] SWAMP Group, Ocean Wave Modeling. Plenum Press: New York, 1985.

[27] H. Mitsuyasu, R. Nakayama, and T. Komari, "Observations of the winds and waves in Hakata Bay,” Rep. Res. Inst. Appl. Mech., Kyushu Univ., vol. 19, pp. 37-74, 1971.

[28] K. Hasselmann, T.P. Barnett, E. Bouws, H. Carlson, D.E Cartwright, K. Enke, J.A. Ewing, H. Gienapp, D.E. Hasselmann, P. Kruseman, A. Meerburg, P. Mller, D.J. Olbers, K. Richter, W. Sell, and H. Walden, "Measurements of wind-wave growth and swell decay during the Joint North Sea Wave Project (JONSWAP)," Ergnzungsheft zur Deutschen Hydrographischen Zeitschrift Reihe, A(8) (Nr. 12), 1973, p. 95.

[29] T.P. Barnett, and K.E. Kenyon, "Recent advance in the study of wind waves," Rep. Prog. Phys., vol. 38, pp. 667-729, 1975.

[30] S. Mandal, "A numerical wave prediction model DOLPHIN: theory and test results". Report no 3-85, Delft. Univ. Tech., The Netherlands, 1985, p. 68.

[31] N.M. Anand, S. Mandal, V. Sanilkumar, and B.U. Nayak, "Real time wave measurements and wave hindcasting in deep waters," Indian J. Marine Sci., vol. 23, pp. 184-186, 1994.

[32] WAMDI Group, "The WAM model- a third generation ocean wave prediction model", J. Phys. Oceanogr., vol. 18, pp. 1775-1810, 1988.

[33] G.J. Komen, L. Cavaleri, M. Donelan, K. Hasselmann, S. Hasselmann, and P.A.E.M. Janssen, Dynamics and modelling of ocean waves, Cambridge Univ. Press, Cambridge, 1994.

[34] N. Booij, L.H. Holthaijsen, and R.C. Ris, "A third-generation wave model for coastal regions. 1 . Model description and validation", $J$. Geophys. Res., vol. 104(C4), pp. 7649-7666, 1999.

[35] H.L. Tolman, User Manual and System Documentation of WAVEWATCHIII version 1.18, NOAA/NWS/NCEP/OMB technical note 166, 1999, p. 100.

[36] A. Herman, R. Kaiser and H.D. Niemeyer, Wind-wave variability in a shallow tidal sea- Spectral modeling combined with neural network methods, Coastal Eng., vol. 56, pp. 759-772, 2009.

[37] V.G. Polnikov, Y.A. Volkov, and F.A Pogarskii, "Numerical wind wave model with a dynamic boundary layer. Nonlinear Processes in Geophysics", Eur. Geophys. Soc., vol. 9, pp. 367-372, 2002.

[38] S. Rao, and S. Mandal, "Hindcasting of storm waves using neural networks", Ocean Eng., vol. 32, pp. 667-684, 2005.

[39] M.J. Varkey, R. Vaithiyanathan, and K. Santanam, "Wind fields of storms from surface isobars for wave hindcasting", In: Int. Conf. Ocean Eng. (ICOE' 96), IIT Madras, 1996 pp. 502-506.

[40] I.R. Young, "Parametric Hurricane wave prediction model", $J$. Waterways Port Coast. Ocean Eng., vol. 114(5), pp. 637-652, 1988.

[41] P. Jain, and M.C. Deo, "Artificial Intelligence tools to forecast ocean waves in real time", The Open Ocean Eng. J., vol. 1, pp. 1320, 2008. [Online] Available: www.bentham.org/ open/tooej/openaccess $2 . h t m$

[42] P. Jain and M.C. Deo, "Real-time wave forecasts off the western Indian coast", Appl. Ocean Res., vol. 29, pp. 72-79, 2007. 